\title{
Using soil-based and physiographic variables to improve stand growth equations in Uruguayan forest plantations
}

\author{
Cecilia Rachid-Casnati ${ }^{(1)}$, \\ Euan G Mason ${ }^{(2)}$, \\ Richard C Woollons ${ }^{(2)}$
}

\section{Introduction}

The afforested area in Uruguay grew at a fast rate since the Forestry Law of 1987 provided legal and tax incentives to the sector. Soils prioritized by law occupy 4,420,000 ha currently, and almost a quarter of this area has been planted. Eucalyp tus grandis is the most commonly planted species in the country (over 250,000 ha), managed in long rotations for saw logs and plywood production in the North and part of the Central regions, and in short rotations for pulp mills in the West. Pinus taeda is the most planted species in the North (nearly 190,000 has), but it is also present

\begin{abstract}
Information provided by traditional growth models is an essential input in decision making processes for managing planted forests. They are generally fitted using inventory data guaranteeing robustness and simplicity. The introduction of explanatory factors affecting tree development in age-based sigmoidal growth and yield equations attempts not only to improve the quality of predictions, but also to add useful information underpinning forest management decisions. This study aimed to assess the use of the following soil-based and physiographic predictors: potentially available soil water (PASW), elevation (Elev), aspect $(\alpha)$ and slope $(\beta)$ in a system of empirical stand equations comprising: dominant height $\left(\mathrm{h}_{\mathrm{dom}}\right)$, basal area $(\mathrm{G})$, maximum diameter at breast height $\left(\mathrm{d}_{\max }\right)$, and standard deviation of diameters $\left(\mathrm{SD}_{\mathrm{d}}\right)$. Augmented models were compared with the base models through precision and bias of estimations for two contrasting species: Pinus taeda (L.), and Eucalyptus grandis (Hill ex. Maiden), planted commercially in Uruguay. Soil-based and physiographic information significantly improved predictions of all the state variables fitted for $E$. grandis, but just $h_{\text {dom }}$ and $G$ for $P$. taeda. Only PASW was consistently significant for the augmented models in $P$. taeda and $E$. grandis, while the contribution of other predictors varied between species. From a physiological point of view, predictors on the augmented models showed consistency. Models with such augmentation produced decrease of errors between 3 to $10.5 \%$, however decreases in the prediction errors calculated with the independent dataset were lower. Results from this study contributed to add information to the decision-making process of plantations' management.
\end{abstract}

Keywords: Forest Modelling, Soil Variables, Physiographic Variables, Pinus taeda, Eucalyptus grandis

in smaller areas in the West. In all cases the species is managed for saw logs.

To manage plantations efficiently, it is necessary to use tools that provide accurate growth and yield information, as well as an understanding of the main factors that help differentiate growth and yield between and within regions. It is of special interest to include information that would allow simulations on climate changing scenarios. Age-based sigmoidal equations representing tree growth and yield, fitted using sample plot data usually guarantee robustness and simplicity to these models, but at the expense of some explanatory
(1) Forestry Research Programme, National Institute of Agricultural Research (INIA Uruguay). Road 5, Km 386, 45000 Tacuarembó (Uruguay); (2) School of Forestry, University of Canterbury, Private Bag 48000, Christchurch (New Zealand)

@ Cecilia Rachid-Casnati (crachid@tb.inia.org.uy)

Received: Jul 19, 2018 - Accepted: Mar 16, 2019

Citation: Rachid-Casnati C, Mason EG, Woollons RC (2019). Using soil-based and physiographic variables to improve stand growth equations in Uruguayan forest plantations. iForest 12: 237-245. - doi: 10.3832/ifor2926-012 [online 2019-05-03]

Communicated by: Emanuele Lingua ability. In this sense, the introduction of factors affecting tree development in growth and yield equations attempts not only to improve the quality of stand projections, but also to add useful information underpinning forest management decisions.

A selection of site-specific climatic, physiographic and/or soils-based characteristics, are often considered in assessing productivity (Weiskittel et al. 2011) and also to improve growth and yield projections. Different strategies have been explored to use this information for augmenting mensurational equations: Woollons et al. (1997) tested the inclusion of solar radiation, rainfall, minimum and maximum temperature, and soil type to project mean top height and basal area of Pinus radiata in New Zealand. There was improvement only for basal area when rainfall and solar radiation were included in equations fitted by soil type. Other approaches (as opposed to age) have used structural indices to make growth more dependent on climatic and soil inputs. Snowdon et al. (1999) derived several climatic indices from two physiological models for incorporating annual variations in climatic factors into a Schumacher projection model for stand basal area of Pinus radiata. They compared dif- 
Tab. 1 - Climate characteristics: values corresponding to the period 1980-2009 (Castaño et al. 2011). $\left(\mathrm{A}_{\mathrm{f}}\right)$ : accumulated days with frosts; $\left(\mathrm{RH}_{\mathrm{y}}\right)$ : annual air relative humidity; (ETP): Penman-Monteith evapotranspiration.

\begin{tabular}{lcccccc}
\hline Descriptor & $\begin{array}{c}\text { Rainfall } \\
(\mathbf{m m})\end{array}$ & $\begin{array}{c}\text { Temp. } \\
\left({ }^{\circ} \mathbf{C}\right)\end{array}$ & $\begin{array}{c}\mathrm{A}_{\mathrm{f}} \\
(\text { days })\end{array}$ & $\begin{array}{c}\text { Radiation } \\
\left(\mathrm{h} \mathrm{day}^{-1}\right)\end{array}$ & $\begin{array}{c}\mathrm{RH}_{\mathrm{y}} \\
(\%)\end{array}$ & $\begin{array}{c}\text { ETP } \\
\left(\mathbf{m m} \text { month }^{-1}\right)\end{array}$ \\
\hline Mean & 1400 & 17.7 & 30 & 7 & 74 & 1100 \\
Maximum & 1600 & 22.6 & 40 & - & 78 & 1200 \\
Minimum & 1200 & 12.9 & 20 & - & 70 & 1000 \\
\hline
\end{tabular}

ferent forms of a generalised Schumacher difference equation with these indices, and found that results were improved with an annual growth index derived from a "process-based" model. Based on this work, Henning \& Burk (2004) used growth indices derived from physiological models as factors to improve growth and yield estimates of an empirical model. They found that these external growth indices were effective in reducing bias in basal area estimations, but were less effective in improving precision. Maestri (2003) studied the inclusion of modifiers for a von BertalanffyRichards equation for modelling dominant height in Eucalyptus grandis, concluding that rainfall, potential evapotranspiration, and maximum and minimum temperature were the most significant explanatory variables of annual increment. However, he also found that error reductions using water balance information were not higher than the error reductions obtained by using simpler environmental variables.

The objective of this work was to assess the contribution of soil-based and physiographic attributes such as: potentially available soil water (PASW), elevation (Elev), aspect $(\alpha)$, and slope $(\beta)$, to a system of mensurational stand equations. Those variables are surrogates of key growth drivers such as radiation, soil moisture, and temperature, and have the advantage to be readily available for their use in forestry planning. Based on this background, we hypothesize that the inclusion of this information would improve precision and bias of predictions of height, basal area, and diameter dynamics for Eucalyptus grandis and Pinus taeda. Therefore, a comparison between models augmented with this information as opposed to base models without such augmentation is presented.

\section{Methods}

Growth and yield equations were fitted for predicting mean top height or dominant height $\left(\mathrm{h}_{\mathrm{dom}}\right)$, and basal area (the sum of basal area of all trees in a hectare, G) for two species commercially planted in Uruguay, namely: Pinus taeda and Eucalyptus grandis. Growth and yield equations for maximum diameter at breast height $\left(\mathrm{d}_{\max }\right)$, and standard deviation of diameter at breast height $\left(\mathrm{SD}_{\mathrm{d}}\right)$ were also analysed since they are necessary to project diameters distributions by the method of moments using an inverse Weibull function (Kuru et al. 1992).

\section{Study area}

Based on the Koppen-Geigen classification system, the climate in Uruguay is tropical-sub humid without marked variations across the country. This is caused by its position respect to both the Pacific and Atlantic Oceans, and the absence of prominent mountain ranges (Castaño et al. 2011). Even though rainfall is well distributed during the year, it has a highly irregular pattern. The main climate features are presented in Tab. 1.

The study was developed in the northern Uruguay, between $30^{\circ} 50^{\prime}$ and $32^{\circ} 49^{\prime} \mathrm{N}$ and $53^{\circ} 43^{\prime}$ and $58^{\circ} 21^{\prime} \mathrm{W}$ in three of the zones prioritized for forestry according to the Forestry Law of 1987 (no. 15939). Those areas were defined on production characteristics and limitations of the soils mainly oriented to cattle and wool. Soils with similar production characteristics are grouped in broad categories defined by a number, and plantations occur mainly in groups $7,8,9$, and 2 (Fig. 1). Parent soil materials of the group 7 (North) comprise reddish sandstones to rose and white argillaceous sandstones. Soils are classified as leached and unsaturated (acrisols and luvisols - Altamirano et al. 1976). With some exceptions, soils are deep, reaching 1.5 to $3 \mathrm{~m}$, acidic, with elevated levels of exchangeable aluminum, and low in base saturation (MGAP/ RENARE 1994). Very shallow weakly developed soils (lithosols) are also found mostly on the hill tops. Group 9 in the West (corresponding to group 9 and o9) is highly variable regarding parent geological material and this is reflected in the variability of soil characteristics. Nonetheless they are mostly sandy stones, developing soils classified as leached saturated, characterized by strong textural differentiation between $\mathrm{A}$

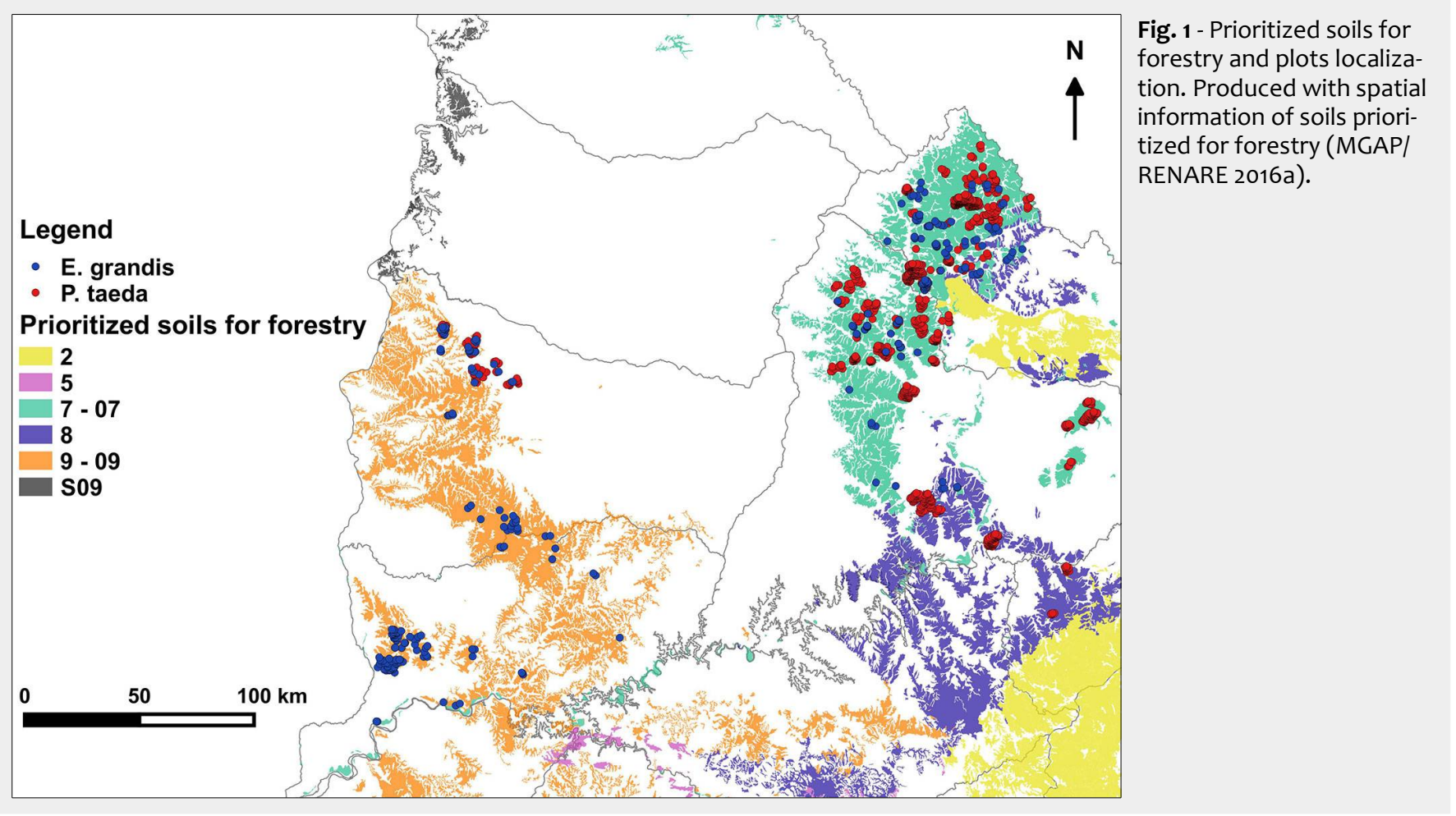


Fig. 2 - Range of water potentially available for PSPs of both species. Produced with spatial information of potentially available soil water (1:1.000.000 scale map - MGAP/ RENARE 2016b).

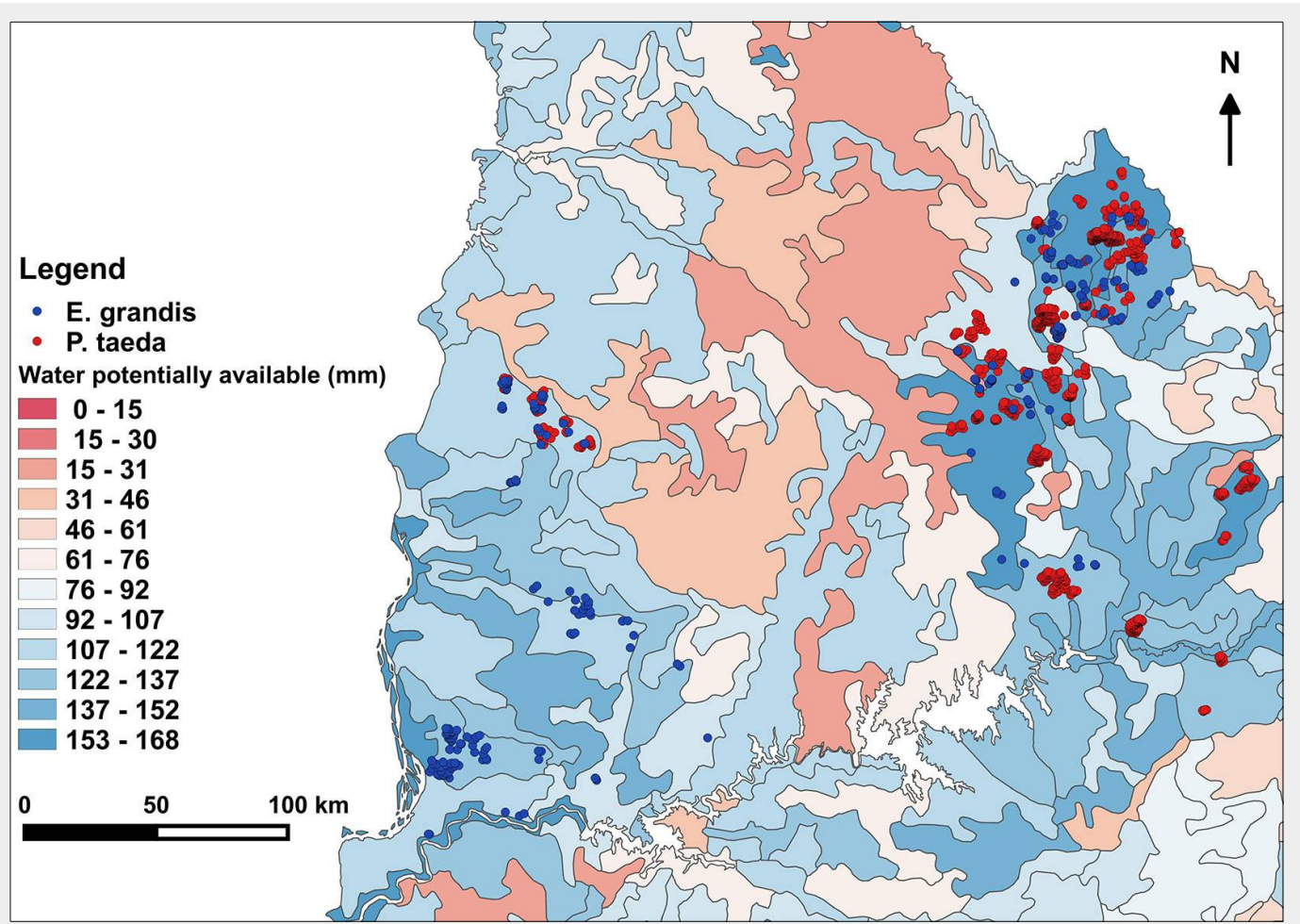

and B horizons (planosols and argisols), and melanic (brunosols - Altamirano et al. 1976). The Central area corresponding to group 8 comprises sandstones. Soils are generally sandy with low fertility. Classification varies from leached unsaturated (luvisols), leached saturated (argisols), melanic (brunosols), and weakly developed and shallow (lithosols - Altamirano et al. 1976). Soils of Groups 8 and 9 are comparatively shallower and more fertile than Group 7.

\section{Data preparation}

Information from 974 permanent sample plots (PSP) in geo-referenced locations in areas prioritized for forestry was used to fit the equations (Fig. 1). P. taeda's plots (669) corresponded to commercial plantations while the E. grandis plots (305) were from commercial plantations and pruning, thinning, and breeding trials of the $\mathrm{Na}$ tional Institute of Agricultural Research (INIA Uruguay). Only PSPs with more than two measurements and with locations georeferenced were included in the dataset.

PSPs were linked to the following site characteristics: aspect $(\alpha)$, slope $(\beta)$, elevation (Elev), and potentially available soil water (PASW), using information publicly available through the Ministry of Cattle, Agriculture, and Fisheries (MGAP/RENARE 2016a). For aspect, slope, and elevation, a digital elevation model with a precision of $30 \times 30 \mathrm{~m}$ was used (MGAP/RENARE 2016b).

Aspect was decomposed to North-South and East-West components by calculating the sine and cosine of the azimuth angle, respectively. In this way sine values range from 1 to -1 from East to West, and cosine values range from 1 to -1 from North to South. Both components were weighted by the slope using the method proposed by Stage (1976), so that the value for flat ground is 0 and it increases along with the slope. Therefore, variables obtained were $\alpha_{s}=\sin (\alpha) \cdot \beta$, and $\alpha_{c}=\cos (\alpha) \cdot \beta$. Potentially available soil water (PASW) was extracted directly from a digital national map (Fig. 2) developed by Molfino \& Califra (2001) based on the 1:1.000.000 Soil Classification Map of Uruguay (MGAP/DSF 1976). The cited authors calculated PASW for each soil profile type through pedotransfer functions developed for the country to compute water potentially available (between $1 / 10$ to $15 \mathrm{~atm})$. The values were calculated for each sub-horizon's depth per soil type and weighted for the percentage that the soil type occupies on each of the 99 soil classification units. Finally, Molfino \& Califra (2001) applied a correction factor that

accounts for limiting factors such as erosion, rockiness, stoniness, and salinity to get a value of net PASW. The range of all 4 studied predictors across the plots is depicted in Tab. S1 (Supplementary material). Procedures involving georeferenced information were developed using QuantumGis (QGIS Development Team 2015), and ArcGis for Desktop (ESRI 2013).

Datasets for both species were screened by graphical methods before and after computing the required variables, to assess the relationship between variables. The variable $h_{\text {dom }}$ was calculated as the mean height of the 100 trees with the largest $d$ within a hectare using Garcia's formula (García 1998) to calculate the number of trees in each PSP equivalent to 100 trees per hectare. Seventy percent of the plots were used for fitting purposes while 30\%

Tab. 2 - Summary of the dataset used for modelling. $(N)$ : total number of sites; $(n)$ : mumber of plot measurements; (PSP): permanent sample plots; (G): basal area; (SD): standard deviation.

\begin{tabular}{|lcccccccc}
\hline \multirow{2}{*}{ Variable } & \multicolumn{1}{c}{ P. taeda } & \multicolumn{7}{c}{ E. grandis } \\
\cline { 2 - 10 } & Mean & Min & Max & SD & Mean & Min & Max & SD \\
\hline $\mathrm{N}$ & - & - & 669 & - & - & - & 305 & - \\
\hline $\mathrm{n}$ & 4.00 & 2.00 & 11.00 & - & 4.00 & 2.00 & 11.00 & - \\
\hline $\mathrm{t}$ (years) & 7.13 & 2 & 25.9 & 3.2 & 6.95 & 1.18 & 18.7 & 3.47 \\
\hline $\mathrm{h}_{\text {dom }}(\mathrm{m})$ & 10.6 & 2.2 & 27 & 4.65 & 21.2 & 4.4 & 46.6 & 7.86 \\
\hline $\mathrm{d}_{\mathrm{m}}(\mathrm{cm})$ & 17.2 & 2.3 & 41.9 & 7.56 & 17.6 & 3.1 & 45.2 & 7.18 \\
\hline $\mathrm{d}_{\text {max }}(\mathrm{cm})$ & 21.1 & 4 & 46.7 & 8.71 & 24.3 & 5 & 62.6 & 8.77 \\
\hline $\mathrm{d}_{\min }(\mathrm{cm})$ & 12.8 & 0.48 & 36.6 & 6.92 & 10.1 & 0.1 & 41.1 & 6.64 \\
\hline $\mathrm{SD}_{\mathrm{d}}(\mathrm{cm})$ & 2.2 & 0.11 & 8.42 & 0.96 & 3.42 & 0.64 & 10.5 & 1.43 \\
\hline $\mathrm{G}\left(\mathrm{m}^{2} \mathrm{ha}^{-1}\right)$ & 15.6 & 0.1 & 53.6 & 10.9 & 19.2 & 0.78 & 58.1 & 8.95 \\
\hline $\mathrm{N}\left(\mathrm{stems} \mathrm{ha}^{-1}\right)$ & 624 & 100 & 1667 & 180 & 886 & 87 & 1775 & 393 \\
\hline $\mathrm{PSP}$ size $\left(\mathrm{m}^{2}\right)$ & 338 & 200 & 500 & 84 & 682 & 400 & 2250 & 315 \\
\hline
\end{tabular}


were utilized for validation. A dataset was also prepared for hypothesis testing using only the longest interval of each plot of the entire dataset. The information of PSPS coverage is presented in Tab. 2.

\section{Growth equations}

For modelling growth of $h_{\text {dom }}, G, d_{\max }$, and $\mathrm{SD}_{\mathrm{d}}$, several differential equations in polymorphic and anamorphic form were tested (see Tab. S2 and Tab. S3 in Supplementary material). Those were fitted using non-linear least-squares as applied by Clutter (1963) using all possible intervals within PSPs. Mixed effects models are sometimes employed to account for multiple measurements within plots, but in this study the problems related to data serial correlation were avoided by testing the inclusion of new variables using a correlation-free dataset where only one interval per plot was included. In this way, valid hypothesis testing was undertaken.

Candidate equations were compared through the root of the mean square error (RMSE), as a measure of precision; and the mean residual (MR) and mean absolute bias (MAB) as a measure of bias. All three statistics calculated using the modelling dataset were ranked and an overall rank for each model was computed by summing the rank values for all the statistics. The best ranked model for each state variable ( $\mathrm{h}_{\mathrm{dom}}, \mathrm{G}, \mathrm{d}_{\max }$, and $\mathrm{SD}_{\mathrm{d}}$ ) was selected. Normality was analysed graphically through histograms and Q-Q plots, and plots of residuals against the variables fitted and the independent variables were also assessed. After selecting the equation for each state variable, the inclusion of predictors was tested using the hypothesis testing dataset. Once the predictors to include were known all the equations were re-fitted using the modelling dataset. The behaviour of augmented models was assessed by plotting projections for contrasting growth conditions.

For the validation stage, plots of residuals (predicted vs. independent values) were examined to detect bias. Confidence intervals for the slopes of predicted $v s$. independent values with a level of significance of $5 \%$ were computed to compare the actual slope with the ideal slope of 1 (Goulding 1979). Comparisons of approaches were done through goodness of fit statistics as well as statistics of prediction (using the validation dataset) for each type of equation (simple and augmented) and comparing residuals.

\section{Results}

\section{Growth equations}

Correlations between the soil-based and physiographic variables and site index were initially assessed using the hypothesis testing dataset. High correlation between explanatory variables could interfere in determining the precise effect of each predictor and lead to large standard errors of the parameters. For P. taeda very low correlations were found between site variables; PASW and Elev, and Elev and $\beta$ are the highest correlated with coefficients slightly over 0.3 in both cases. Moreover, none of the site variables showed high correlations with site index. Higher correlations were found with the eucalypt species; the same variables PASW and Elev, as well as Elev and $\beta$ gave correlation coefficients of 0.84 and 0.60 respectively, whereas between PASW and $\beta$ the coefficient was 0.47. Additionally, it was found that PASW and Elev had the highest correlations to $\mathrm{SI}$ ( 0.63 and 0.68 respectively). The use of correlated predictors was avoided.

For both species the inclusion of a dummy variable (Z7) to distinguish growth in Zone 7 compared to the rest (Zones 9 and 8) was assessed in base models as applied by Methol (2001), for models currently available. For the pine species, Elev was the site variable most correlated with the dummy (0.59), whereas correlation with SI was very low (0.16). For E. grandis, correlation was high between $\mathrm{Z} 7$ and Elev (0.88) and PASW (0.80), while the correlation with $\beta$ was less evident (0.54).

\section{Base models}

In general, models that showed the best fit were polynomial forms of von Bertalanffy-Richards and Schumacher. Base models selected for Pinus taeda were as it follows (eqn. 1 to eqn. 4 ):

$$
\begin{aligned}
& h_{\text {dom }_{2}}=a\left(\frac{h_{d o m_{1}}}{a}\right)^{\ln \left(1-e^{-b t_{2}}\right)} \\
& \ln \left(1-e^{\left.-b t_{1}\right)}\right. \\
& G_{2}=e^{\ln G_{1}\left(\frac{t_{1}}{t_{2}}\right)^{c}+a\left(1-\left(\frac{t_{1}}{t_{2}}\right)^{c}\right]} \\
& d_{\text {max }}=e^{\ln d_{m_{\text {max }}}\left(\frac{t_{1}}{t_{2}}\right)^{c}+\left(a_{0}+a_{1} S I\right)\left[1-\left(-\frac{t_{1}}{t_{2}}\right)^{c}\right]} \\
& S D_{d_{2}}=a\left(\frac{S D_{d_{1}}}{a}\right)^{\frac{\ln \left(1-e^{-b t_{2}}\right)}{\ln \left(1-e^{-b t_{1}}\right)}}
\end{aligned}
$$

whereas base models adjusted for Eucalyptus grandis were (eqn. 5 to eqn. 8):

$$
\begin{aligned}
& h_{d o m_{2}}=e^{\ln H_{d o m_{1}}\left(\frac{t_{1}+k}{t_{2}+k}\right)+\left(a_{0}+a_{1} Z 7\right)\left(1-\frac{t_{1}+k}{t_{2}+k}\right)}
\end{aligned}
$$

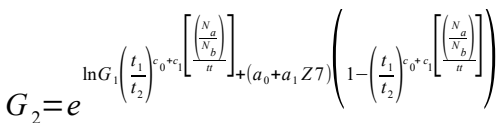

$$
\begin{aligned}
& d_{\text {max }}=e^{\ln d_{\max }\left(\frac{t_{1}}{t_{2}}\right)^{c_{0} c_{1} 27}+\left(a_{0}+a_{1} Z 7\right)\left[1-\left(\frac{t_{1}}{t_{2}}\right)^{c_{0}+c_{1} 27}\right]}
\end{aligned}
$$$$
S D_{d_{2}}=\left(a_{0}+a_{1} Z 7\right)\left(\frac{S D_{d_{1}}}{a_{0}+a_{1} Z 7}\right)^{\frac{\ln \left(1-e^{-b t_{2}}\right)}{\ln \left(1-e^{-b b_{1}}\right)}}
$$

For $P$. taeda there were very modest or no improvements of the $h_{\text {dom }}$ equations tested by adding the dummy variable, but for E. grandis its inclusion improved both precision and bias. For this species, a parameter (k) was added to $t_{1}$ and $t_{2}$ (eqn. 5 ), giving the equation known as the Johnson-

$$
d_{\text {max }}=e^{\ln d_{\max }\left(\frac{t_{1}}{t_{2}}\right)^{\sigma_{0}+c_{1} \alpha_{s}}+\left(\omega+a_{2} \alpha_{s}\right)\left[1-\left(\frac{t_{1}}{t_{2}}\right)^{\sigma_{0}+c_{1} \alpha_{s}}\right]}
$$$$
S D_{d_{2}}=\left(a_{0}+a_{1} \alpha_{s}\right)\left(\frac{S D_{d_{1}}}{a_{0}+a_{1} \alpha_{s}}\right)^{\frac{\ln \left(1-e^{-b t_{2}}\right)}{\ln \left(1-e^{-b_{1}}\right)}}
$$

Schumacher (Grosenbaugh 1965). This modification substantially improved bias precision while the equation still pre and consistency (Clutter et al. 1983). For thinning modifier (ratio of stocking per by the time of thinning: $\left[\mathrm{N}_{\mathrm{a}} / \mathrm{N}_{\mathrm{b}}\right] / \mathrm{tt}-$ sessed. For the pine species, this term was not significant in the model and was not included. For $E$. grandis the term was signifi. For modelling P. taeda's $d_{\max }$, site in $\operatorname{dex}(S I)$ was introduced in the equation to

\section{Augmented models}

Augmented equations for $h_{\text {dom }}$ and $G$ for Pinus taeda were as it follows (eqn. 9, eqn.

$$
\begin{aligned}
& h_{d o m_{2}}=\left(\omega+a_{2} \text { Elev }\right)\left(\frac{h_{\text {dom }}}{\omega+a_{2} \text { Elev }}\right)^{\frac{\ln \left(1-e^{-b t_{2}}\right)}{\ln \left(1-e^{-h_{1}}\right)}} \\
& G_{2}=e^{\ln G_{1}\left(\frac{t_{1}}{t_{2}}\right)^{c}+\left(\omega+a_{2} \alpha_{c}+a_{3} \text { Elev }\right)\left[1-\left(\frac{t_{1}}{t_{2}}\right)^{c}\right]}
\end{aligned}
$$

where $\omega=a_{0}+a_{1}$ PASW

列 not improved error for the pine species; ever, site variables would be indirectly introduced in $\mathrm{d}_{\max }$ (eqn. 3) if $\mathrm{SI}$ was calculated using the augmented equation for $\mathrm{h}_{\text {dom }}$ (eqn. 9).

for Eucalyptus grandis augmented models 14):

$h_{d o m_{2}}=e^{\ln h_{\text {dom }}\left(\frac{t_{1}+k}{t_{2}+k}\right)+\left(\omega+a_{2} \alpha_{c}+a_{3} \alpha_{s}\right)\left(1-\frac{t_{1}+k}{t_{2}+k}\right)}$

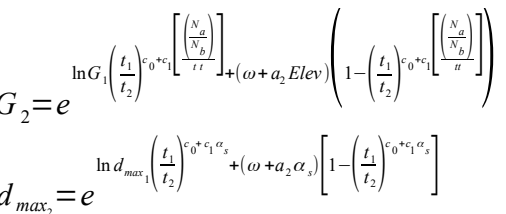

PASW was significant for all state variables except for $\mathrm{SD}_{\mathrm{d}}$, whereas aspect modified by slope was not significant for $G$. The dominant height curves fitted corresponded to the trajectories of the entire dataset for each species (Fig. 3). For the case of $E$. grandis, plots located in the northern part of the country $(Z 7=1)$ eral.

An analysis of the influence of the site variables included in P. taeda's equations showed that higher growth rate was achieved for $h_{\text {dom }}$ in sites with higher elevation and higher PASW values (Fig. 4). For basal area, East aspects on steeper terrain and larger water storage capacity would favour growth (Fig. 4). For E. grandis, the projecting basal area, the inclusion of a divide after thinning and before thinning 

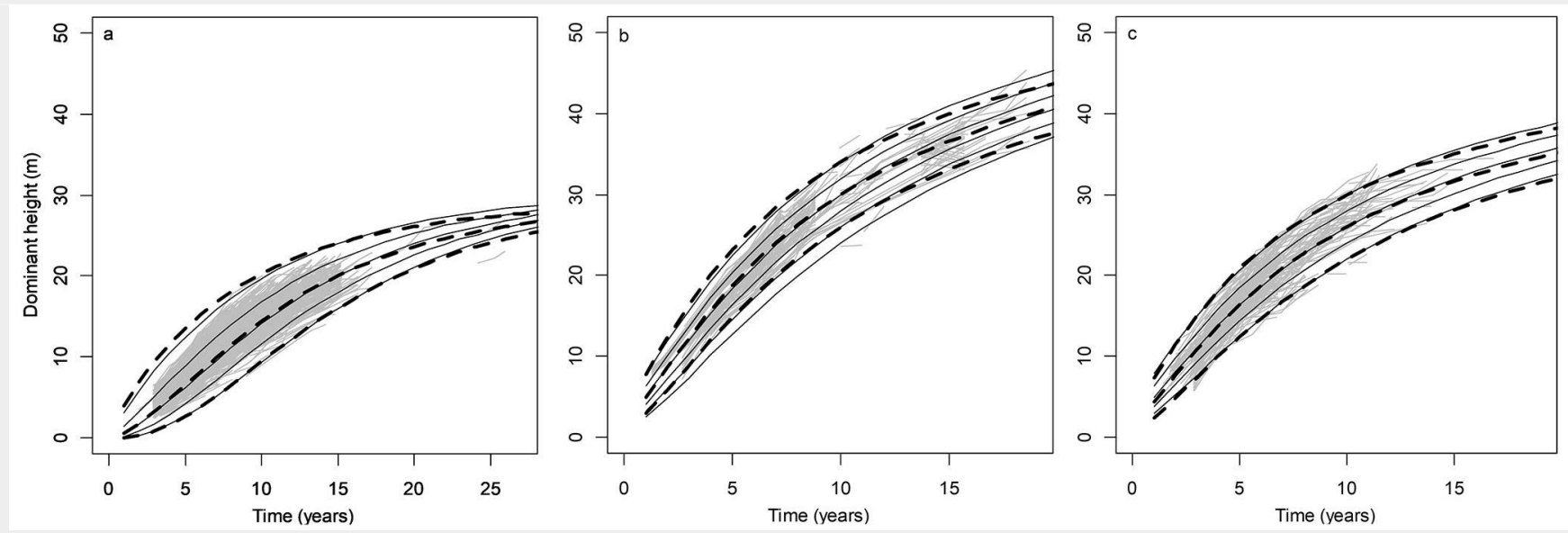

Fig. 3 - Dominant height curves using base equations (continued black lines), with original plot trajectories (grey lines), and a com parison with augmented equations (dashed lines), for P. taeda (a), and E. grandis planted in Zone 7 (b), and other Zones (c). Average values of site variables were applied for each Zone.

Fig. 4 - Effect of site variables on growth curves for P. taeda: dominant height for elevation values of $150 \mathrm{~m}$ (thick) and 65 $\mathrm{m}$ (thin). Basal area for elevation values of $150 \mathrm{~m}$ (thick line) and $65 \mathrm{~m}$ (thin lines), and $5 \%$ slopes facing $\mathrm{E}$ (dashed) and facing $W$ (dotted).

Fig. 5 - Effect of site variables on growth curves for $E$. grandis: dominant height for slopes of $9 \%$ facing NE (dashed) and SW (dotted). Basal area for elevation values of $130 \mathrm{~m}$ (thick) and $172 \mathrm{~m}$ (thin lines); maximum diameter and standard deviation for $5 \%$ slopes facing East (dashed) and West (dotted).
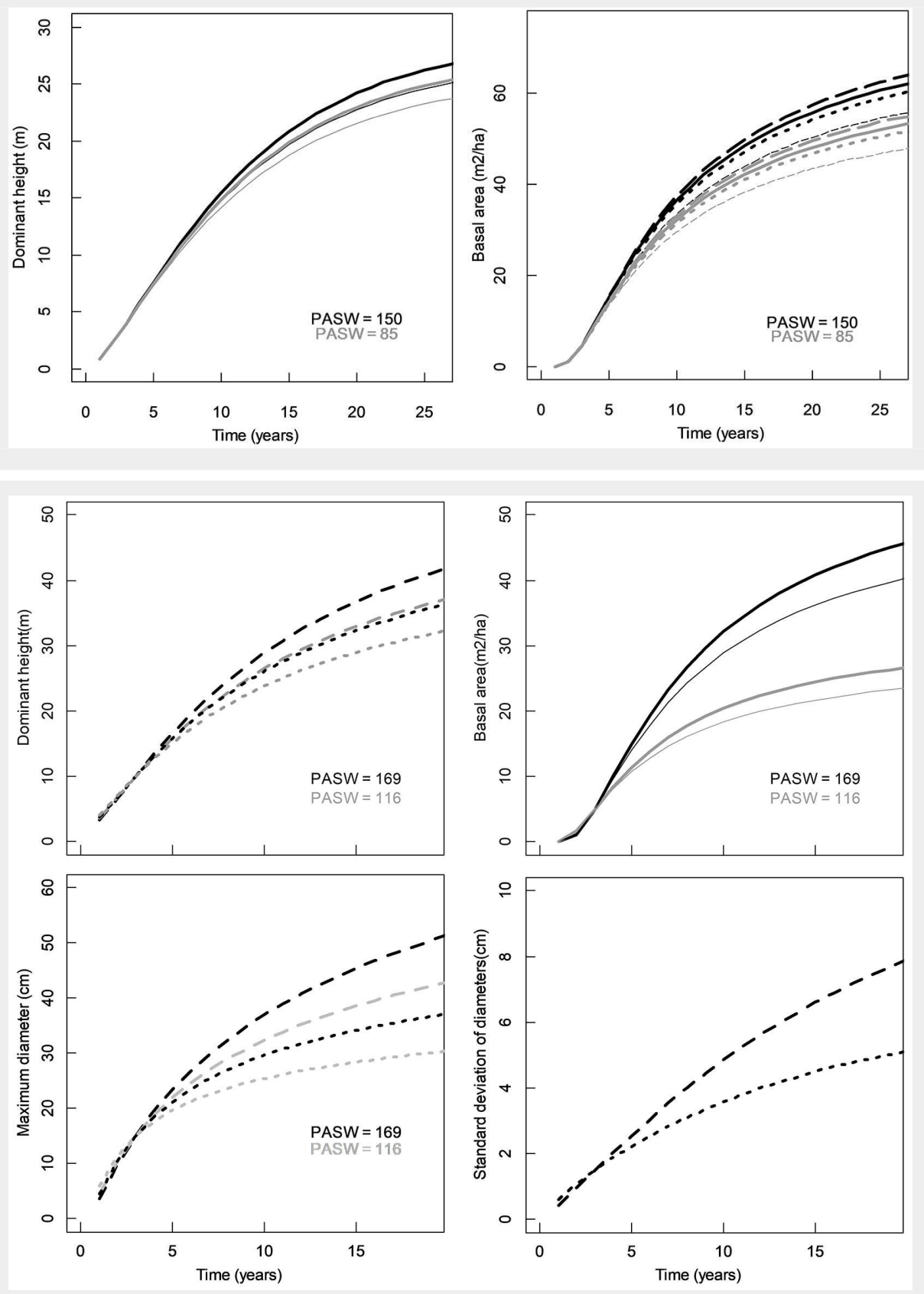
Tab. 3 - Comparison of RMSE for base and augmented models for each state variable, using the modelling dataset and an independent dataset.

\begin{tabular}{|c|c|c|c|c|c|c|c|}
\hline \multirow[b]{2}{*}{ Species } & \multirow[b]{2}{*}{ Variable } & \multicolumn{3}{|c|}{ Modelling dataset } & \multicolumn{3}{|c|}{ Independent dataset } \\
\hline & & Base & Augmented & $\begin{array}{c}\Delta R M S E \\
(\%)\end{array}$ & Base & Augmented & $\begin{array}{c}\Delta R M S E \\
\text { (\%) }\end{array}$ \\
\hline \multirow[t]{4}{*}{ P. taeda } & $\mathrm{h}_{\mathrm{dom}}(\mathrm{m})$ & 0.894 & 0.867 & -3.0 & 0.860 & 0.850 & -1.0 \\
\hline & $G\left(m^{2} h a^{-1}\right)$ & 3.151 & 2.929 & -7.0 & 3.230 & 3.130 & -3.1 \\
\hline & $\mathrm{d}_{\max }(\mathrm{cm})$ & 1.789 & - & - & 2.080 & - & - \\
\hline & $\mathrm{SD}_{\mathrm{d}}(\mathrm{cm})$ & 0.484 & - & - & 0.470 & - & - \\
\hline \multirow[t]{4}{*}{ E.grandis } & $\mathrm{h}_{\text {dom }}(\mathrm{m})$ & 1.785 & 1.685 & -5.6 & 1.690 & 1.660 & -1.8 \\
\hline & $\mathrm{G}\left(\mathrm{m}^{2} h \mathrm{~h}^{-1}\right)$ & 2.847 & 2.677 & -6.3 & 2.760 & 2.650 & -4.0 \\
\hline & $\mathrm{d}_{\max }(\mathrm{cm})$ & 2.179 & 1.951 & -10.5 & 2.220 & 2.180 & -1.8 \\
\hline & $\mathrm{SD}_{\mathrm{d}}(\mathrm{cm})$ & 0.516 & 0.494 & -4.3 & 0.556 & 0.560 & 0.7 \\
\hline
\end{tabular}

$\mathrm{h}_{\mathrm{dom}}$ equation projects higher growth rate for NE orientation in steeper terrains with high values of PASW (Fig. 5). For basal area, the equation predicts higher growth in sites with higher values of PASW and lower Elev (Fig. 5). From a physiological point of view the model shows consistency, especially regarding the effect of water holding capacity of soils on growth for both species. The example plots also show differences in $\mathrm{h}_{\text {dom }}$ growth with respect to PASW between both species; when for $P$. taeda the increase in growth by increasing $65 \mathrm{~mm}$ of PASW is approximately $2 \mathrm{~m}$ of height and $5 \mathrm{~m}^{2}$ ha-1 at the age 20, for $E$. grandis an increase of $53 \mathrm{~mm}$ represents around $5 \mathrm{~m}$ and $20 \mathrm{~m}^{2}$ ha-1 of increase in height and basal area, respectively. This reflects the differences in growth rate of those two species and the relationship between growth and potential availability of resources.

For $\mathrm{d}_{\max }$, site variables PASW and $\alpha_{\mathrm{s}}$ included in the $E$. grandis' equation affects such that stands located in soils with elevated levels of water storage capacity and steeper terrains facing East show larger maximum diameters (Fig. 5). $\mathrm{SD}_{\mathrm{d}}$ of this species increases its magnitude in sites facing East (Fig. 5). Statistics of fit and parameters of fitted models for each state variable are presented as Supplementary material (Tab. S4 to Tab. S7).

Tab. 4 - Comparison of MAB for base and augmented models for each state variable, using the modelling dataset and an independent dataset.

\begin{tabular}{|c|c|c|c|c|c|}
\hline \multirow{2}{*}{ Species } & \multirow{2}{*}{ Variable } & \multicolumn{2}{|c|}{ Modelling dataset } & \multicolumn{2}{|c|}{ Independent dataset } \\
\hline & & Base & Augmented & Base & Augmented \\
\hline \multirow[t]{4}{*}{ P. taeda } & $\mathrm{h}_{\mathrm{dom}}(\mathrm{m})$ & 0.69 & 0.67 & 0.67 & 0.66 \\
\hline & $G\left(m^{2} h a^{-1}\right)$ & 2.25 & 2.13 & 2.53 & 2.21 \\
\hline & $\mathrm{d}_{\max }(\mathrm{cm})$ & 1.32 & - & 1.52 & 1.49 \\
\hline & $\mathrm{SD}_{\mathrm{d}}(\mathrm{cm})$ & 0.34 & - & 0.32 & 0.32 \\
\hline \multirow[t]{4}{*}{ E. grandis } & $\mathrm{h}_{\mathrm{dom}}(\mathrm{m})$ & 1.32 & 1.28 & 1.29 & 1.27 \\
\hline & $G\left(m^{2} h a^{-1}\right)$ & 2.00 & 1.90 & 2.05 & 2.05 \\
\hline & $\mathrm{d}_{\max }(\mathrm{cm})$ & 1.61 & 1.45 & 1.58 & 1.55 \\
\hline & $\mathrm{SD}_{\mathrm{d}}(\mathrm{cm})$ & 0.38 & 0.37 & 0.41 & 0.41 \\
\hline
\end{tabular}

carbon allocation to roots. Their results showed that for the species, water availability strongly influences the capture and use-efficiency of supplies. For P. taeda, Albaugh et al. $(1998,2004)$ found that stem growth efficiency (growth per LAI unit) as well as total biomass production efficiency increased by irrigation, and hypothesised that the increase occurred as a consequence of more biomass being allocated to photosynthesizing tissue. Given the importance of water availability for plant growth, a range of variables related to soil moisture, available water for stands, or rainfall has been tested before on differential equations or when modelling increments (Woollons et al. 1997, Snowdon et al. 1999, Pinjuv et al. 2006, Ritchie \& Hamann 2008) proving to be effective especially for improving $G$ predictions. The tendency of a larger decrease in errors for $G$ compared to $h_{\text {dom }}$ was also observed in this study.

The variable PASW used in this analysis is rather theoretical based on a coarse resolution 1:1.000.000 soil map, however it synthesises solidly a series of essential soil characteristics, yielding consistent results with respect to forest productivity. Furthermore, this variable represents potential water availability without interfering on the path invariance property of differential equations, which is a fundamental characteristic to provide robustness to mensurational models.

The effect of slope and aspect on growth varies depending on the species requirements and site characteristics that result from the interaction of mean annual temperature, rainfall regimes, altitude, and velocity and wind-direction (Werling \& Tajchman 1984, Verbyla \& Fisher 1989, Kimsey et al. 2008). Aspect weighted by slope ( $\alpha_{s}$ and $\alpha_{c}$ ) was consistent for $E$. grandis equations, whereas for P. taeda it was significant only for G. NE and E aspect favoured growth and the effect was accented by the slope. We hypothesize that sunlight duration in northern slopes is longer in such latitudes $\left(30^{\circ}\right.$ to $\left.33^{\circ} \mathrm{S}\right)$, leading to longer period for photosynthesizing as well as warmer temperatures in winter, especially for $E$. gran- 
dis. Given that rainfall is abundant in general (1200 to $1600 \mathrm{~mm}$ year $\left.{ }^{-1}\right)$, desiccation would not pose a systematic problem for growth during warm months. Although this hypothesis should be tested, similar behaviour was reported by Running (1984), who simulated growth of conifers in the northern hemisphere. He observed that in the cases when water was not restricted, energy was the factor limiting physiological activity; therefore, southern slopes produced higher seasonal photosynthesis. Although the use of sine and cosine of the azimuth angle as well as their association with slope has been used for predicting site index (Trimble \& Weitzman 1956, Stage 1976) and stand volume (Stage \& Salas 2007), the use in differential growth equations is unusual.

Elevation has no explicit effect on growth but influences key growth factors such as temperature and soil moisture at a local scale. It has been used specifically in mountainous areas for forecasting site productivity (Monserud \& Moody Breuer 1990, Fontes et al. 2003), being incorporated as an explanatory variable in yield equations for predicting $h_{\text {dom }}, G$, and $d_{\max }$ (Mason et al. 1997). Because differences in altitude are relatively small in terms of the impact on site-specific temperature, an alternative hypothesis is that there is a negative influence of soil moisture in lower ground for $P$. taeda, since the species is frequently planted in marginal, low areas which are waterlogged for short periods. This was investigated graphically by using categorical information of drainage speed and results showed that plots located in sites classified as slow and medium drainage speed were associated with smaller values of altitude (e.g., less than $150 \mathrm{~m}$ ), which would confirm the first hypothesis. Although elevation could be a surrogate of drainage for $P$. taeda, further research should be undertaken to confirm this hypothesis as well as testing the correspondence of altitude with climate variables such as temperature.

\section{Advantages of augmented models}

The augmented models represent an increase in flexibility of curves by including predictors on the shape parameters, the asymptote, or both. Although reductions of the prediction error (calculated using an independent dataset) were modest ( 2 to $4 \%$ ), bias was reduced by augmentation of most equations.

To date, models used in Uruguay do not consider site characteristics explicitly. Prognosis systems for Eucalyptus grandis and Pinus taeda in the country use dummy variables to account for differences on growth curves. Dummy variables have been used by Methol (2001) for modelling $\mathrm{h}_{\mathrm{dom}}$ and $\mathrm{G}$ for the same eucalypt species in Uruguay, distinguishing growth curves for zones 7, 8, and 9 (Fig. 1). Moreover, Methol (2006) localized growth curves for $h_{\text {dom }}$ for Eucalyptus globulus ssp. globulus growing in the zones 2 and 9. Zonification has been used traditionally as a way to characterize a set of regional attributes related mainly to geology, topography, and soils. However, this has been traditionally developed for cattle production, and not for forestry, which poses limitations for characterizing potential forest productivity. For P. taeda, instead, zonification has not seemed to be effective and has not been applied in the past (Ferraz Filho et al. 2015, Rachid-Casnati \& Hirigoyen 2015). Main advantages in using augmented equations rely in the possibility to represent differences in site quality in a more descriptive way than with the localization strategy. This benefits the understanding of growth and allows the improvement of site and species management (e.g., assessing the benefits of improving water holding capacity of soils by subsoiling or assisting in the selection of pines vs. eucalypts). Further contribution of this work would be on the identification of areas where growth could be favoured or reduced due to variations in rainfall regimes under climate change scenarios and the quantification of such variations. It is expected that the methodology proposed here will be favoured with future improvements on the resolution of water holding capacity maps and digital terrain models.

\section{Use of the equations and constraints}

Explanatory components of the models add utilities for forest management, and the information needed is readily available with its quality tending to improve over time. However, care must be taken when using the equations when site variables border on the extremes of the range of values used in this study, especially when using a combination of extreme values. Representation of all possible combinations of explanatory variables' values is a common issue in forest modelling since the set of PSPs used is restricted. To take a closer look to this potential problem, the extreme values of site variables were plotted against all the values of each of the remaining site variables used, to search for information gaps. Results showed that PSPs combining extreme values of the predictors were rare for the eucalypt species (i.e., extreme values of a site variable were commonly combined with average values of the rest); however, because the range of aspects in the plots presented no constraints, the main relationship to investigate was PASW and $\beta$ extremes. In this sense, PSPs located in sites with $\beta$ larger than $9 \%$ are very scarce; there are no PSPs with slopes larger than $9 \%$ in sites with low PASW (less than 100mm). For P. taeda, elevation should also be taken into consideration: extreme combinations were available in the dataset for PASW, $\beta$ and large values of Elev, whereas low values of Elev were strictly associated with low PASW (100mm) and average $\beta(5 \%)$. Forthcoming research should be directed to include permanent sample plots located in extreme sites to achieve more reliable models under such marginal sites.

Models for both species were adjusted using a dataset comprising a diverse genetic base, covering a large part of the variability for the country. This contributes to the generalization capacity of the models, however adaptations of certain genotypes to sites can occur. Interactions between genotypes and environments were not assessed and are not contemplated in the models.

An information gap was found for $P$. taeda near harvesting age, therefore care must be taken when performing projections beyond 16 years. Future work should consider updating datasets to include stands at harvesting age for this species.

\section{Conclusions}

Augmented stand level growth equations have been developed and can be recommended to be incorporated in a prognosis system to simulate height, basal area, and diameter dynamics for Pinus taeda and Eucalyptus grandis growing in northern Uruguay. Soil-based and physiographic information improved predictions of the variables fitted for $E$. grandis: $h_{\text {dom }}, G, d_{\max }$, and $S D_{d}$, but were significant only for $h_{d o m}$ and $G$ in the case of $P$. taeda.

The use of explanatory variables (physiographic and soil variables) decreased the fitting error in a range from 3 to $10.5 \%$, however decreases in the prediction errors calculated with the independent dataset were much lower ranging from 1.6 to $4 \%$. In this sense, main advantage of the augmented models relies on the better description of site differences and their effect on tree growth, consequently adding new possibilities to the use of those models for plantations' management.

\section{Acknowledgements}

The authors are indebted with the companies that generously have provided data for this study: Global Forest Partners LP and Cambium S.A., Cloverly S.A., Bosques del Sur S.A., and UPM-Forestal Oriental. We also acknowledge the Directorate of Renewable Resources (RENARE) of the Ministry of Cattle, Agriculture, and Fisheries (MGAP) for contributing with physiographic and soil information. Finally, we thank the reviewers whose valuable comments greatly improved this manuscript. Funding for this study was provided by the Ministry of Foreign Affair and Trade of New Zealand, through NZAid Scholarship, and INIA Uruguay.

\section{References}

Albaugh TJ, Allen HL, Dougherty PM, Kress LW, King JS (1998). Leaf area and above- and belowground growth responses of loblolly pine to nutrient and water additions. Forest Science 44: 317-328. [online] URL: http://academic.oup. com/forestscience/article/44/2/317/4627497

Albaugh TJ, Allen HL, Dougherty PM, Johnsen 
$\mathrm{KH}$ (2004). Long term growth responses of loblolly pine to optimal nutrient and water resource availability. Forest Ecology and Manage ment 192: 3-19. - doi: 10.1016/j.foreco.2004.01. 002

Altamirano A, Da Silva H, Durán A, Echevarría A, Panario D, Puentes R (1976). Carta de Reconocimiento de Suelos del Uruguay, Tomo I: Clasificación de suelos [Soil Survey of Uruguay, Vol 1: Soil Classification]. MAP-DSF, Montevideo, Uruguay, pp. 96. [in Spanish]

Castaño JP, Giménez A, Ceroni M, Furest J (2011). Caracterización agroclimática del Uruguay 1980-2009 [Climatic characterization of Uruguay 1980-2009]. Technical Series 193, INIA, Montevideo, Uruguay. pp. 34. [in Spanish]

Clutter JL (1963). Compatible growth and yield models for loblolly pine. Forest Science 9: 354370. [online] URL: http://academic.oup.com/for estscience/article-abstract/9/3/354/4746653

Clutter JL, Fortson JC, Pienaar LV, Brister GH, Bailey RL (1983). Timber management: a quantitative approach ( $1^{\text {st }}$ edn). John Wiley and Sons, USA, pp. 333. [online] URL: http://www. cabdirect.org/cabdirect/abstract/19840691762

ESRI (2013). ArcGis for Desktop. Environmental Systems Research Institute, Redlands, CA, USA. Ferraz Filho AC, Scolforo JRS, Oliveira AD, Mello JM (2015). Modeling growth and yield of loblolly pine stands under intensive management. Pesquisa Agropecuária Brasileira 50: 707717. - doi: 10.1590/S0100-204X2015000800009 Fontes L, Tom M, Thompson F, Yeomans A, Luis JS, Savill P (2003). Modelling the Douglas-fir (Pseudotsuga menziesii (Mirb.) Franco) site index from site factors in Portugal. Forestry 76 : 491-507. - doi: 10.1093/forestry/76.5.491 García O (1998). Estimating top height with variable plot sizes. Canadian Journal of Forest Research 28: 1509-1517. - doi: 10.1139/x98-128

Goulding CJ (1979). Validation of growth models used in forest managament. New Zealand Journal of Forestry 24: 108-124.

Grosenbaugh LR (1965). Generalization and reparameterization of some sigmoid and other nonlinear functions. Biometrics 21: 708-714. doi: $10.2307 / 2528551$

Henning JG, Burk TE (2004). Improving growth and yield estimates with a process model derived growth index. Canadian Journal of Forest Research 34: 1274-1282. - doi: 10.1139/x04-021

Kimsey MJ, Moore J, McDaniel P (2008). A geographically weighted regression analysis of Douglas-fir site index in north central Idaho. Forest Science 54: 356-366. [online] URL: http://academic.oup.com/forestscience/article/ 54/3/356/4604418

Kuru GA, Whyte AGD, Woollons RC (1992). Utility of reverse Weibull and extreme value density functions to refine diameter distribution growth estimates. Forest Ecology and Management 48: 165-174. - doi: 10.1016/0378-1127(92) 90128-V

Landsberg JJ, Sands P (2011). Physiological ecology of forest production ( $1^{\text {st }}$ edn). Terrestrial Ecology Series, Elsevier, USA, pp. 331.

Maestri R (2003). Modelo de crescimento e produção para povoamentos clonais de Eucalyptus grandis considerando variáveis ambientais [Modelling growth and yield of clonal Eucalyptus grandis using environmental variables]. PhD thesis, Federal University of Paraná, Curitiba, Brazil, pp. 143. [in Portuguese]

Mason EG, Whyte AGD, Woollons RC, Richardson $B$ (1997). A model of the growth of juvenile radiata pine in the Central North Island of New Zealand: links with older models and rotationlength analyses of the effects of site preparation. Forest Ecology and Management 97: 187195. - doi: 10.1016/S0378-1127(97)00099-6

Methol R (2001). Comparisons of approaches to modelling tree taper, stand structure and stand dynamics in forest plantations. PhD thesis, University of Canterbury, Christchurch, New Zealand, pp. 298.

Methol R (2006). SAG globulus: sistema de apoyo a la gestion de plantacions de Eucalyptus globulus [SAG globulus: decision-support system for managing Eucalyptus globulus' plantations]. Technical Series 158, INIA, Montevideo, Uruguay, pp. 34. [in Spanish]

MGAP/DSF (1976). Carta de reconocimiento de suelos del Uruguay Escala 1:1.000.000 [Soil Survey Map 1:1.000.000]. MGAP, Montevideo, Uruguay, pp. 1. [in Spanish]

MGAP/RENARE (1994). Indices de productividad de suelos [Soil productivity indices]. CONEAT Groups, MGAP, Montevideo, Uruguay, pp. 183. [in Spanish]

MGAP/RENARE (2016a). Cartas Temáticas [Thematic cartography]. MGAP, Montevideo, Uruguay, Web site. [in Spanish] [online] URL: http://www.mgap.gub.uy/unidad-organizativa/ direccion-general-de-recursos-naturales/tramit es-y-servicios/biblioteca-digital/cartas-tematicas MGAP/RENARE (2016b). Modelo Digital de Terreno [Digital Terrain Model]. Web site. [in Spanish] [online] URL: http://www.mgap.gub.uy/uni dad-organizativa/direccion-general-de-recurs os-naturales/tramites-y-servicios/bibliotecadigital/modelo-digital-del-terreno

Molfino JH, Califra A (2001). Agua disponible de las tierras del Uruguay [Available soil water in Uruguay]. MGAP, Montevideo, Uruguay, pp. 12. [in Spanish] [online] URL: http://www.mgap. gub.uy/sites/default/files/multimedia/agua_disp onible_de_las_tierras_del_uruguay.pdf Monserud RA, Moody Breuer DW (1990). A soilsite study for inland Douglas-fir. Canadian Journal of Forest Research 20: 686-695. - doi: 10.113 9/×90-092

Pinjuv G, Mason EG, Watt M (2006). Quantitative validation and comparison of a range of forest growth model types. Forest Ecology and Management 236: 37-46. - doi: 10.1016/j.foreco.20 06.06 .025

QGIS Development Team (2015). QGIS geographic information system. Open Source Geospatial Foundation Project, web site. [online] URL: http://www.qgis.org/en/site/

Rachid-Casnati AC, Hirigoyen A (2015). SAG taeda: sistema de apoyo a la gestión de plantaciones de Pinus taeda [SAG taeda: decision-support system for managing Pinus taeda's plantations]. Technical Series 224, INIA, Montevideo, Uruguay, pp. 22. [in Spanish]

Ritchie MW, Hamann JD (2008). Individual-tree height-, diameter- and crown-width increment equations for young Douglas-fir plantations. New Forests 35: 173-186. - doi: 10.1007/s11056007-9070-7

Running SW (1984). Microclimate control of for- est productivity: analysis by computer simulation of annual photosynthesis/transpiration balance in different environments. Agricultural and Forest Meteorology 32: 267-288. - doi: 10.1016/0168-1923(84)90054-6

Snowdon P, Jovanovic T, Booth TH (1999). Incorporation of indices of annual climatic variation into growth models for Pinus radiata. Forest Ecology and Management 117: 187-197. - doi: 10.1016/S0378-1127(98)00463-0

Stage AR, Salas C (2007). Interactions of elevation, aspect, and slope in models of forest species composition and productivity. Forest Science 53: 486-492. [online] URL: http:// academic.oup.com/forestscience/article/53/4/4 $86 / 4604065$

Stage AR (1976). Notes: an expression for the effect of aspect, slope, and habitat type on tree growth. Forest Science 22: 457-460.

Stape J, Binkley D, Ryan MG (2004). Eucalyptus production and the supply, use and efficiency of use of water, light and nitrogen across a geographic gradient in Brazil. Forest Ecology and Management 193 (1-2): 17-31. - doi: 10.1016/j.for eco.2004.01.020

Temu MJ (1992). Forecasting yield of Douglas fir in the south island of New Zealand. PhD thesis, University of Canterbury, Christchurch, New Zealand, pp. 249.

Trimble GR, Weitzman S (1956). Site index studies of upland oaks in the Northern Appalachians. Forest Science 2: 162-173.

Verbyla DL, Fisher RF (1989). Effect of aspect on ponderosa pine height and diameter growth. Forest Ecology and Management 27: 93-98. doi: 10.1016/0378-1127(89)90031-5

Weiskittel AR, Hann DW, Kershaw JA, Vanclay JK (2011). Forest growth and yield modeling. John Wiley and Sons, Honoken, NJ, USA, pp. 415. Werling JA, Tajchman SJ (1984). Soil thermal and moisture regimes on forested slopes of an Appalachian watershed. Forest Ecology and Management 7: 297-310. - doi: 10.1016/0378-1127(84) 90006-9

Woollons RC, Snowdon P, Mitchell ND (1997). Augmenting empirical stand projection equations with edaphic and climatic variables. Forest Ecology and Management 98: 267-275. - doi: 10.1016/S0378-1127(97)00090-X

\section{Supplementary Material}

Fig. S1 - Residuals using the validation dataset for $h_{\text {dom }}$ for $P$. taeda's base (a) and augmented equations (b), and for $E$. grandis' base (c), and augmented function (d).

Fig. S2 - Residuals using the validation dataset for $G$ for P. taeda's baseline (a) and augmented equations (b), and for $E$. grandis' baseline (c), and augmented equations (d).

Fig. S3 - Residuals using the validation dataset for $d_{\max }$ and $S D_{d}$ for $P$. taeda base functions.

Fig. S4 - Residuals using the validation dataset for $d_{\max } E$. grandis' base (a), and augmented functions (b). 
Fig. S5 - Residuals using the validation Tab S3 - Anamorphic forms of equations

dataset for $S D_{d}$ for $E$. grandis base (a), and tested. augmented equations (b).

Tab S1 - Distribution of plots across predictors' ranges.

Tab S2 - Polymorphic forms of equations tested.
Tab. S4 - Parameters of the equations selected for modelling $\mathrm{h}_{\text {dom }}$.

Tab. S6 - Parameters of the equations selected for modelling $d_{\max }$.

Tab. S5 - Parameters of the equations Link: Rachid-Casnati_2926@supploo1.pdf selected for modelling $\mathrm{G}$. 